\title{
Why is it important to use algae in aquaculture?
}

\author{
Nihed Ben Halima* \\ Biological Engineering Department, National School of Engineers of Sfax, University of Sfax, Sfax-Tunisia
}

\begin{abstract}
Algae and especially microalgae are very promising into eventual biotechnological applications. Indeed, microalgae are unique compared to other living organisms thanks to their valuable biochemical compounds for aquaculture, human health food, biofuels and other applications. Recently, studies on the oleaginous microalgae, for instance, those from the genus Chlorella, have emerged their uses for commercial exploitations with applications focused on nutrition and aquaculture uses. Chlorella minutissima has outstanding features in health and nutrition; and it could play an important part in aquaculture improvement methods as it produces significant amount of polyunsaturated fatty acids.

Microalgae are considered to be among the promising feedstocks for aquaculture in the future. For this end Chlorella minutissima is an oil-rich green alga, was studied in many reports as a source of long chain n-3 polyunsaturated fatty acids (n-3 LC-PUFA) to replace control diet without microalgae for rotifers, which serve in turn as food for early stages of fish.
\end{abstract}

Keywords: Aquaculture, Chlorella minutissima, Fish, Nutrition, Polyunsaturated fatty acids.

Accepted on 5 October, 2017

\section{Introduction}

Aquaculture as the science of cultivating aquatic animals, plants and related organisms like fish, shellfish, seaweed and microalgae, for human use and consumption. The cultivation of these marine or freshwater organisms procures generally under controlled conditions. Due to a significant increase in global demand for fish and seafood, aquaculture would be a fast growing industry. Indeed, there is a progressively increase in world demand for seafood, from $9.9 \mathrm{~kg}$ per capita in the $1960 \mathrm{~s}$ to $19.7 \mathrm{~kg}$ in 2013 , and preliminary estimates exceeding $20 \mathrm{~kg}$ per capita in 2015 [1]. For this end, aquaculture is essential to satisfy the increase in fish and seafood demand because fishing solely is no longer sufficient to this increase in demand. Fishing has generally remained stable for more than 10 years, whereas aquaculture production increased at an average rate of $23.5 \%$ from 2009 to 2014. Moreover, the total fish harvested from aquaculture amounted to 73.8 million tons in 2014. In fact, approximately $44 \%$ of consumed fish are farmed at present, but this percentage is predicted to reach $52 \%$ by 2025 [1].

Fisheries and aquaculture are among the most important socioeconomically sectors in Tunisia, a North African country located on the Southern coast of the Mediterranean with more than $1300 \mathrm{~km}$ of coastline. Aquaculture in Tunisia is mainly marine-oriented, with annual production of almost 10000 tons in 2014, according to the statistical Department of Fisheries and Aquaculture in Tunisia [2]. The reared species with higher economic value are European seabass (Dicentrarchus labrax), Thicklip grey mullet (Chelon labrosus) and Thin-lipped grey mullet (Liza ramada), for instance, market prices per $\mathrm{kg}$ of Dicentrarchus labrax range from 9-12 TND (Tunisian Dinar) which correspond to about 3.66-4.88 € [3]. Nowadays, many authors are focused on performing Life Cycle assessment (LCA) of seafood production to provide new insights into its environmental impacts and therefore to improve environmental sustainability of the aquaculture production systems $[3,4]$.

\section{Microalgae in aquaculture}

Microalgae are promising living cells, which are represented at the base of the aquatic food chain due to their important nutritional value [5]. They are able to synthesize important organic molecules such as lipids by using sunlight and carbon dioxide [6]. Thus, microalgae would realize an important role in aquaculture. The first reports of the cultivation of microalgae as feed in aquaculture were published since 1910 [7] and since then today, the use of microalgae in aquaculture has developed intensively [8,9]. Aquaculture is a growing industry, and therefore, the industry of culturing microalgae is consequently increasing. The main applications of microalgae in aquaculture could relate directly or indirectly to the nutrition impacts on various species of aquatic farmed organisms such as rotifers and fish. Indeed, microalgae could be used directly, for instance, as food for larvae of some gastropods or as food for some fish species in their earliest growth stages [10]. Also, microalgae could be used indirectly, for instance, as food for zooplankton such as rotifers which are essential food for some fish larvae [11]. In aquaculture, microalgae were found to be applicable in so called "Green water" feeding technique, wherein microalgae are added as a suspension to the organism's environment grown simultaneously in tanks with larvae [5,12].

Otherwise, microalgae are recognized as the next generation sustainable feedstock $[13,14]$ especially due to their beneficial biochemical compounds like lipids and carotenoids.

\section{Importance of Chlorella minutissima}

The most important algal species are Chlorella, which are used as nutrient source in aquaculture production worldwide [15]. 
Chlorella belongs to the green algae group and is being granted GRAS (generally recognized as safe) status.

Chlorella minutissima is a unicellular microalga without flagella recognized as an oil-rich green alga that exhibits many attractive features, such as easy cultivation, fast growth, and high levels of amino acids and polyunsaturated fatty acids (PUFA's). These attractive characteristics make Chlorella minutissima as a potential microalga in pharmaceuticals and health foods [16].

Falaise et al. have reviewed that Chlorella are versatile as they play important roles as antimicrobial agent's like anti-bacterial, antifungal and antiviral activities against related diseases in aquaculture. For this end the "green water" technique is a useful tool against bacterial disease in aquaculture [17]. The same authors highlighted that microalgae are able to improve the life-food quality, by reducing the number of associated pathogenic bacteria and decreasing the risk of transmission to fish larvae.

Antibacterial compounds from microalgae can be lipids or fatty acids. An anti-marine bacterial activity was demonstrated in vitro with the polyunsaturated fatty acid (PUFA) such as the PU free FA in P. tricornutum, identified as eicosapentaenoic acid [18].

PUFAs, such as Arachidonic acid (AA) (20:4 omega-6), eicosapentaenoic acid (EPA) (20:5 omega-3) and docosahexaenoic acid (DHA) (22:6 omega-3) are essential for the growth and survival of marine fish larvae [19]. In fact, fish larvae have a very limit ability to synthesize PUFAs, which must be derived from zooplankton such as rotifers that consume algae [20]. In rotifers production, microalgae could increase the DHA and EPA contents of the rotifers even with a short-term enrichment period. However, to observe more positive effects on growth and survival of fish larvae using rotifers with short term enrichment in microalgae, microalgae need also to be added as "green water" [21].

\section{Current and Future Developments}

In previous report, some of identified patents focus on algal lipids were included in a review that emphasis the promising insight into lipids from algae [22]. In perspective trial, we envisage studying the effects of Chlorella minutissima on a Tunisian aquaculture farm. The objective of such study is so to examine the influence of Chlorella minutissima, givens as supplement to fish feed on the productive performance and the sensory evaluation of many tested fishes. Firstly, we will focus on cultural conditions of algal biomass; then, we will balance the experimental diets for total PUFAs especially EPA+DHA, n-3/n-6 ratio and total Saturated fatty acids (SFA) in order to elucidate specific dietary effects of the microalgae components on lipid and energy metabolism of rotifers and general fish condition. Besides production performance, fillet quality of the tested fishes will also be examined [23-27].

\section{Consent for Publication}

Not applicable.

\section{Conflict of Interest}

The author confirms that this article content has no conflict of interest.

\section{Acknowledgements}

Declared none.

\section{References}

1. FAO. The state of world fisheries and aquaculture: Contributing to food security and nutrition for all. Food and Agriculture Organization of the United Nations, 2016.

2. DGPA. Annuaire des statistiques des pêches en Tunisie. Ministère de l'Agriculture, Tunisie. 2014.

3. Abdou K, Aubin J, Romdhane MS, et al. Environmental assessment of seabass (Dicentrarchus labrax) and seabream (Sparus aurata) farming from a life cycle perspective: A case study of a Tunisian aquaculture farm. Aquaculture. 2017;471:204-12.

4. Ziegler F, Hornborg S, Green B S, et al. Expanding the concept of sustainable seafood using Life Cycle Assessment. Fish Fish. 2016;17:1073-93.

5. Brown MR, Jeffrey SW, Volkman JK, et al. Nutritional properties of microalgae for mariculture. Aquaculture. 1997;151:315-31.

6. Fuentes-Grünewald C, Alacid E, Garcés E, et al. Biomass and lipid production of dinoflagellates and raphidophytes in indoor and outdoor photobioreactors. Mar Biotechnol. 2012;15:37-47.

7. Allen EJ, Nelson EW. On the artificial culture of marine plankton organisms. J Mar Biol Assoc. 1910;8421-74.

8. Duerr EO, Molnar A, Sato V. Cultured microalgae as aquaculture feeds. J Mar Biotechnol. 1998;6:65-70.

9. Santos-Ballardo DU, Rossi S, Hernández V, et al. A simple spectrophotometric method for biomass measurement of important microalgae species in aquaculture. Aquaculture. 2015;448:87-92.

10. Brown M, Robert R. Preparation and assessment of microalgal concentrates as feeds for larval and juvenile pacific oyster (Crassostrea gigas). Aquaculture 2002;207:289-309.

11. Welladsen H, Kent M, Mangott A, et al. Shelf-life assessment of microalgae concentrates: effect of cold preservation onmicroalgal nutrition profiles. Aquaculture 2014;430:241-7.

12. Neori A. Green water microalgae: the leading sector in world aquaculture. J Appl Phycol. 2011;23:143-9.

13. Murray P M, Moane S, Collins C, et al. Sustainable production of biologically active molecules of marine based origin. New Biotechnol. 2013;30(6):839-50.

14. Pérez-López P, González-García S, Jeffryes C, et al. Life cycle assessment of the production of the red antioxidant carotenoid astaxanthin by microalgae: from lab to pilot scale. J Clean Prod. 2014;64:332-44.

15. Skjånes K, Rebours C, Lindblad P. Potential for green microalgae to produce hydrogen, pharmaceuticals and 
other high value products in a combined process. Crit Rev Biotechnol. 2013;33:172-215.

16. Seto A, Wang HL, Hesseltine CW. Culture conditions affect eicosapentaenoic acid content of Chlorella minutissima. J Am Oil Chem. Soc. 1984;61:892-4.

17. Falaise C, François C, Travers MA, et al. Antimicrobial compounds from eukaryotic microalgae against human pathogens and diseases in aquaculture. Mar Drugs. 2016;14:159.

18. Desbois AP, Mearns-Spragg A, Smith VJ. A fatty acid from the diatom Phaeodactylum tricornutum is antibacterial against diverse bacteria including multiresistant Staphylococcus aureus (MRSA). Mar. Biotechnol. 2008;11:45-52.

19. Sargent J, McEvoy L, Estevez A, et al. Lipid nutrition of marine fish during early development: current status and future directions. Aquaculture 1999;179:217-29.

20. Yongmanitchai WC, Ward OP. Omega-3 fatty acidsAlternative sources of production. Process Biochem. 1989;24:117-25.

21. Reitan KI, Rainuzzo JR, Øie G, et al. A review of the nutritional effects of algae in marine fish larvae. Aquaculture. 1997;155:207-21.

22. Ben Halima N. Occurrence and importance of plant lipids: a promising insight into algae. Recent Pat Food Nutr Agric. 2016; 8:166-74.
23. AOAC. Official methods of analysis, The Association of Analytical Chemists. 2000;17.

24. Folch J, Lees M, Sloane Stanley GH. A simple method for the isolation and purification of total lipids from animal tissues. J Biol Chem. 1957;226:497-509.

25. Kjeldahl J. A new method for the determination of nitrogen in organic matter. Journal of Analytical Chemistry. 1883;22:366-82.

26. Mørkøre T, Einen O. Relating sensory and instrumental texture analyses of Atlantic salmon. J Food Sci. 2003;68:1492-7.

27. Pérez-López P, González-García S, Jeffryes C, et al. Life cycle assessment of the production of the red antioxidant carotenoid astaxanthin by microalgae: from lab to pilot scale. J Clean Prod. 2014;64:332-44.

\section{*Correspondence to}

Dr. Nihed Ben Halima

Biological Engineering Department,

National School of Engineers of Sfax,

University of Sfax, Tunisia

Tel: 0021626061987

E-mail: nihedbenhalima@gmail.com 